\title{
Trump Nominates Former Pharmaceutical Executive as HHS Secretary
}

President Trump on Monday announced Alex Azar, a former pharmaceutical executive, as his choice to succeed Dr. Tom Price as secretary of Health \& Human Services (HHS) (1). HHS is an 80,000-employee federal agency that oversees the Centers for Medicare and Medicaid Services, the Food and Drug Administration, the National Institutes of Health, and the Centers for Disease Control and Prevention. Price resigned in September following reports of his extensive use of government and charter air travel.

Azar, a lawyer, formerly headed Eli Lilly \& Co.'s U.S. division. Before that, he served as HHS general counsel and deputy secretary during the George W. Bush administration. During that stint, he received praise for his management competence. Azar "will be a star for better healthcare and lower drug prices!" Trump tweeted.

Andy Slavitt, CMS administrator under the Obama administration, also a lawyer and former United Healthcare executive, offered cautious praise for Azar. "I have reason to hope he would make a good HHS secretary," Slavitt said in a written statement. "He ... has real-world experience enough to be pragmatic, and will hopefully avoid repeating the mistakes of his predecessor in over-politicizing Americans' access to healthcare."

If confirmed, Azar would inherit an agency currently torn by political and policy divisions in the wake of Price's departure (2). He will have to make key decisions to avoid further disruption in the individual health insurance market; how much leeway to give states to make big changes in their Medicaid expansion program; and face pressure to address rising prescription drug costs. One management issue Azar would quickly face is how to deal with Price's ambitious Reimagine HHS initiative to streamline the department's operations and with the White House's proposal to slash the HHS' budget for 2018 by $18 \%$.

Azar has been a sharp critic of the Affordable Care Act, saying in May that the ACA is "fundamentally broken" and "circling the drain." In June, he envisioned the Trump administration shifting the ACA in a more conservative direction even without repeal and replacement of the law. He also has opposed reducing prescription drug prices or allowing purchasing drugs from other countries where prices are lower.

If confirmed, Azar will represent a return to the recent tradition of selecting Secretaries of HHS with no medical background. Before, Price, only Dr. Otis Bowen (1985-9) and Dr. Louis Sullivan (1989-93) were physicians of the 11 noninterim Secretaries.

Richard A. Robbins, MD

Editor, SWJPCC 


\section{References}

1. Meyer H. Can Trump's pick to lead HHS navigate the churning political waters of healthcare? Modern Healthcare. November 13, 2017. Available at:

http://www.modernhealthcare.com/article/20171113/NEWS/171119968?utm source $=$ modernhealthcare\&utm medium $=$ email\&utm content $=20171113$ NEWS-171119968\&utm campaign=am (accessed 11/14/17).

2. Pradhan R, Diamond D. Price investigation continues to roil HHS. Politico. November 13, 2017. Available at:

https://www.politico.com/story/2017/11/13/tom-price-private-jets-probe-hhs$\underline{244793}$ (accessed 11/14/17). 